\title{
Increased Risk of Primary Ovarian Insufficiency by High-Fructose Diet: A 90 Day Hormonal and Immunohistochemical Study in Wistar Rats
}

\section{Roya Mirzaei}

Islamic Azad University

Sepideh Arbabi Bidgoli ( $\sim$ sepieharbabi@gmail.com )

Islamic Azad University https://orcid.org/0000-0003-4830-8680

\section{Roya Khosrokhavar}

Health Network Development Center: Iran Ministry of Health and Medical Education

Shahram Shoeibi

Health Network Development Center: Iran Ministry of Health and Medical Education

Hamidreza Ahmadi Ashtiani

Islamic Azad University

\section{Research Article}

Keywords: High-Fructose-Corn-Syrup, HFCS-55, Fructose, Sweetener, Ovary, Uterine, Testosterone, OECD 408

Posted Date: January 27th, 2022

DOI: https://doi.org/10.21203/rs.3.rs-1188503/v1

License: (c) (i) This work is licensed under a Creative Commons Attribution 4.0 International License. Read Full License 


\section{Abstract}

There is ambiguous evidence that high-fructose diet can induce toxicity in different organ systems but its endocrine disrupting effects by abnormal changes in female reproductive organs is poorly evidenced. This study aimed to address the reproductive safety of high fructose diet through clinical, necropsy biochemical, hormonal, histopathological and immunohistochemical analysis. For this purpose, 5-6 weeks mature female Wistar rats were divided in three groups and each five animals/group exposed to standard chow+ water+ HFCS-55, standard chow+ water +sucrose $75 \% \mathrm{w} / \mathrm{v}$ and standard chow+ water for 90 days. Remarkable increase in most lipid profile factors and total body weights of HFCS- 55 fed rats and sucrose fed rats were detected in similar pattern compared to control .At the same time a battery of differential signs and symptoms in HFCS fed groups including destructive endometrial and ovarian changes , significant increase in FSH and LH levels, meaningful decreased serum testosterone and estradiol levels and strong AR expression in reproductive tissues of HFCS group of animals were recorded compared to other two study groups. These thought-provoking signs and signals of fructose induced reproductive toxicity in this model emphasis the contribution of HFCS- 55 to deteriorated ovarian and endometrial health. More human population studies is necessary to find any possible association between fructose-rich diet and growing incidence of Primary Ovarian Deficiency (POI) in reproductive aged women .Further concern on this public health issue is required to revise existing regulatory standards and prevent this possible threat in human society.

\section{Introduction}

In the last four decades, severe changes in human nutritional patterns and higher consumption of high sugar rich diet have dramatically associated with increased incidence of hyperuricemia, dyslipidemia, hypertension, insulin resistance and overweight/obesity (Akarca-Dizakar SÖ, 2020) . General rising prevalence of obesity is highly associated with increased risk of endocrine disruption as evolving worldwide health crisis in adults and children (Zhou Y, 2021 ). A most recent animal study on rats shows a strong association between early exposures to high-sucrose diet and deteriorated ovarian health (de Melo $G B$, 2021). Higher incidence of total adiposity and truncal subcutaneous fat accumulation have become alerting women health problem with clusters of hormonal dysregulation which can lead to ovarian dysfunction (Ishikawa H, 2018). Prospective cohort studies indicate that routine consumptions of sugar sweetened beverages (SSBs) are closely associated with changes in hepatic metabolism and microbiome changes (Bhat SF, 2021), weight gain ,obesity , metabolic syndrome (Semnani-Azad Z, 2020), (Sadowska J, 2019 ), (Collison KS, 2009 ), and increased risk of Polyc Cystic Ovarian Syndrom (PCOS) (Rizk MG, 2020) over time .Moreover neonatal exposure to SSBs may affect infant growth, predispose them to obesity phenotypes ,altered body composition (Michael I. Goran, 2017) and increased risk of ovarian toxic reactions in later stages of life .

Nowadays, fructose has become the main agent in sugar-sweetened beverages and sweets in many countries (Goncalves MD, 2019). Food industries prefer to use commercial high-fructose-corn-syrup 55\% (HFCS-55) based on its sweetness, palatability, taste enhancement properties (DeChristopher LR, 2020) 
and taste maintaining properties of the beverages and food products (Chenxia Dai, 2020). Routine consumption of HFCS-sweetened beverage in breast feeding mothers increases the concentration of fructose in breast milk (Paige K. Berger, 2018) and fluids from PCOS patients showed significantly higher fructose levels compared to healthy women regardless of whether the follicles were mature or immature (Shi $B, 2020)$. Based in this concept on female susceptibility to fructose induced changes we decided in the present work to find any possible associations between HFCC-55 long-term consumption and any change in serum sex hormone levels, ovarian and uterine histopathological changes and expression levels of sex steroid receptors by immunohistochemical method. We decided here to focus on HFCS-55 in females based on supporting evidence on sex specific effect of fructose in women compared to men after high-fructose exposure (M. Rodgers, 2019)as well as the ubiquitous exposure of human populations to fructose through prepackaged foods, breakfast cereals, baked goods, dairy desserts, ssoft drinks and juice beverages (Zargaraan A, 2016).We compared the hormonal effects of HFCS-55 in original concentration(55\%) with sucrose syrup 75\% using OECD 408 guideline .

\section{Material \& Methods}

\subsection{Study Subjects}

\section{High Fructose Corn Syrup 55 (HFCS-55)}

HFCS- $55 \%$, was kindly provided and certified by Zar Fructose Co., Ltd., Tehran, Iran in March 2020, under the code number of ZFQS04 with confirmed analytical sheet. According to analytical sheet, $100 \mathrm{ml}$ of HFCS-55 provides $71.72 \mathrm{~g}$ carbohydrate (Fructose and Glucose), also the estimated energy of $100 \mathrm{ml}$ of HFCS-55 is $286.9 \mathrm{Kcal}$.

\section{Sucrose Syrup $75 \%$}

Purified and crystallized sucrose (saccharose) with over $99.7^{\circ} \mathrm{Z}$ polarization was provided and certified by Merck Millipore Co., Ltd., Germany under the CAS number of 57-50-1 with accessible analysis sheet in March 2020.Sucrose is made up of one molecule of glucose and one molecule of fructose joined together. It is a disaccharide, a molecule composed of two monosaccharaides: glucose and fructose. Sucrose produces naturally in plants, from which, table sugar refines. Sucrose is the most abundant disaccharide and the major product of photosynthesis. Sucrose syrup $75 \%$ was prepared by dissolving 75 $\mathrm{g}$ Sucrose with properties mentioned above in distilled water and adjusting up to $100 \mathrm{ml}$. We prepared each $100 \mathrm{ml}$ of sucrose syrup $75 \%$ which provides about $280-290$ Kcal energy.

\section{Experimental animals and housing conditions}

This study was carried out in a group of 15 mature regularly cycling female Wistar rats, aged 5-6 weeks, with initial body weights of $165-180 \mathrm{~g}$ which were purchased from Pasture Institute of Iran. Each 5 female rats were housed together in one standard cage in 12-h light/dark cycle (07:00-19:00), $23 \pm 2^{\circ} \mathrm{C}$ temperature, relative humidity of $30-70 \%, 8-15$ times/h air change with access to tap water and standard 
diet ad libitum. The cage cleaning schedule, air filtration and recirculation, health checks and facility maintenance were carried out following to one-week adaptation and acclimation period.

This study was approved by the ethics committee of Islamic Azad University (IR. IAU. TMU REC.1399.216), and the animal care protocol was consistent with the committee's guidelines for the care of animals accordance to the Standard Operating Procedures of Ministry of Health and Medical Education of Iran for the Care and Use of Laboratory Animals and Canadian Council of Animal Care (CCAC) Guidelines for Care and Use of Experimental Animals.

\subsection{Repeated dose oral toxicity study}

The practical model of the experiment was conducted based on OECD 408 toxicology guideline.

After 10 days adaptation period, healthy female rats were randomly divided into 3 groups ( 5 rats/group) and labeled as Fo (HFCS-55), So (Sucrose 75\%), and Co (control) groups. They were given free access to HFCS-water (HFCS group), Sucrose-water (Sucrose group) or deionized water (control group). Water and food consumption, general behavior and body weights were daily measured and recorded. Daily calorie intakes were calculated based on the calories levels in Table 1 and adjusted to the same levels based on the calorie levels obtained from ingested fructose or sucrose and standard rodents chow $(3.34 \mathrm{kcal} / \mathrm{g})$.

Clinical variables were considered as drinking and eating patterns, quality of response to environmental stimuli, surface of body reactions, body hair changes, drowsiness, any change in stool and urine colors, bringing up the tails, abnormal or ataxic gaits, any changes in eyes, salivation, changes in tear and total weight. At day 90 overnight fasted rats were sacrificed after blood collections by heart puncture under light carbon dioxide anesthesia and whole bloods were drawn for further biochemical analysis.

\subsection{Biochemical Analysis}

The collected blood samples were centrifuged at $1500 \mathrm{~g}$ for $15 \mathrm{~min}$ at $4^{\circ} \mathrm{C}$ to obtain serums, and then the whole plasma were isolated and kept at $-80 \mathrm{C}$ until further analysis. The levels of glycemic factors were measured using an auto analyzer (HITACHI 917 / OLYMPUS AU640 \& COBAS INTEGRA). Other than above factors. ,lipid profile of animals was evaluated using serum concentration of total cholesterol, HDL, LDL and ratios using spectrophotometric enzyme assay kits (Amara Siri SS, 2020) in Bahar Toxicology Laboratory in Tehran.

\subsection{Hormonal Assay}

In order to determine the variations in serum concentrations of FSH, LH, Testosterone, Estradiol and progesterone, tail blood samples were collected according to standard protocol at day 15, 30,45,60, 75 and 90 of study and the serum was separated by cold centrifuge and collected in microtubes. Hormone Levels were compared with control by Chemiluminescence Immunoassays (CLIA) method using Cobas E411 from Roche Company with serial number of 15D3-16. 


\subsection{Recovery studies}

A commercial rat serum pool (catalog no. M5905, Sigma Chemical Co., St. Louis, M0) was spiked with various hormone concentrations, and percent recovery and parallelism to the assay standard curve were determined. For each assay, the serum pool was spiked either with hormones across the assay range or vehicle to determine endogenous hormonal levels in the pool. Samples were run in duplicate, and each assay was repeated to confirm results. Hormonal recovery from each spiked sample was determined by subtracting hormone values in vehicle-spiked controls from hormone spiked samples.

\subsection{Necropsy and Histopathological studies}

During necropsy study, reproductive organs including uterus and ovaries were dissected out. Intact organs were rinsed and weighed with physiological serum to remove substances that may interfere with later stages and weighted. Organs were fixed in $10 \%$ formalin solution at the next step. To remove the water, the desired tissue was dehydrated with degrees of alcohol (30, 50, 70, 80, 90 and absolute alcohol). To strengthen the fixed tissues, they were placed in a paraffin blocks and finally 5 micron thin sections were prepared with a microtome. Multiple sections from each block were subsequently prepared at 5-micrometer diameters and stained with hematoxylin and eosin (H\&E) for microscopically evaluations. The sections were examined under the light microscope (Olympus BX-51, Olympus, Tokyo, Japan) by expert animal pathologist and scored.

\subsection{Immunohistochemcial Assay of sex hormone receptors}

As previously described (Bidgoli SA ), (Bidgoli SA, 2011), dewaxed and rehydrated tissue sections were subjected to antigen retrieval using microwave oven and boiling citrate buffer $(\mathrm{pH}=6.0)$. Endogenous peroxidase activity and nonspecific binding sites were blocked by incubating sections by $0.3 \%$ hydrogen peroxide in methanol for $30 \mathrm{~min}$ and $3 \%$ BSA for $60 \mathrm{~min}$, respectively. Sections were then incubated $30 \mathrm{~min}$ at Room Temperature with AR (Clone AR441, Dakocytomation) that recognize the nuclear expression of rat proteins in reproductive tissues. The results were visualized using Opti View DAB detection kit based on the manufacturer's instruction with necessary modifications. Sections were also counterstained with Meyer's haematoxyline. In each series, a section in which incubation with the primary antibody was omitted used as negative control. The ideal staining conditions were established in our preliminary experiments. Staining was considered negative only after careful examination of the entire tissue section. All samples were assessed and scored by two independent pathologists. Histoscores of androgen receptor was assessed according to Intensity score and Allred score $(\mathrm{P}+\mathrm{I})$. In each case, a histoscore with a potential range of $0-$ 300 was calculated as follows:

No immunoreactive cell: negative (0)

$\leq 1 \%$ of cells are immunoreactive: Weak positive $(1+)$

$1-10 \%$ of cells are immunoreactive: Intermediate positive $(2+)$ 
$11-33 \%$ of cells are immunoreactive: Strong positive (3+)

$>34 \%$ of cells are immunoreactive: Very strong positive (4+)

\subsection{Statistical analysis}

Study groups compared with one-way analysis of variance (ANOVA) and Post-hoc test. By student's t-test the difference between two sample means compared. Parametric values were expressed as mean \pm standard deviation (SD) and the level of significance was set at $p<0.05$ in SPSS Statistics Software (version 21).

\section{Results}

\subsection{Clinical Effects}

Clinical variables including quality of response to environmental stimuli, surface of body reactions, body hair changes, drowsiness, any change in stool and urine colors, bringing up the tails, abnormal or ataxic gaits, any changes in eyes, salivation, changes in tear were checked daily and remained unchanged until the end of study.

3.2. Total Body Weight: As described in table 1, the mean \pm SD body weight was significantly increased in HFCS-55 fed group compared to control $(267.62 \pm 4.61 \mathrm{~g}$ vs. $230.52 \pm 0.84 \mathrm{~g}, p=0.0094)$. Similar change was recorded in Sucrose syrup fed group compared to Control $(275.82 \pm 6.6237$ vs. $230.52 \pm 0.84 \mathrm{~g}, p=$ 0.0003).

\subsection{Serum levels of gonadotropins and sex hormones}

Table 1 presents and compares the mean serum levels of FSH, LH and sex hormones (estradiol, progesterone and testosterone) in female rats of the 3 study groups at day 15,30,45,60, 75 and 90. Interestingly serum estradiol level was significantly decreased in HFCS fed animals compared to control $(7.28 \pm 4.55$ vs. $25.12 \pm 14.5, p<0.0001)$ and sucrose fed animals $(7.28 \pm 4.55$ vs. $14.66 \pm 5.7, p<0.005)$. Serum estradiol level was significantly decreased in HFCS fed animals compared to control $(7.28 \pm 4.55$ vs. $25.12 \pm 14.5, \mathrm{p}<0.0001)$ and sucrose fed animals $(7.28 \pm 4.55$ vs. $14.66 \pm 5.7, \mathrm{p}<0.005)$.Daily HFSC-55 consumption significantly decreased serum testosterone levels $(0.0294 \pm 0.002$ vs. $0.222 \pm 0.103, p=0.0032)$ compared to control and sucrose $0.0294 \pm 0.002$ vs $0.1156 \pm 0.102, p=0.0056)$.At the same time progesterone levels significantly increased $(42.04 \pm 16.74$ vs. $17.046 \pm 6.56, p=0.0145)$ compared to control and sucrose $(42.04 \pm 16.74$ vs. $28.79 \pm 20, p=0.0213)$. Significantly higher $\mathrm{LH}(0.14 \pm 0.08)$ and FSH (0.12 \pm 0.01$)$. detected in HFCS animals compared to both control groups .In general an upward trend in the serum concentrations of FSH, $\mathrm{LH}$ and progesterone in HFCS receiving animals and a downward trend in Estradiol and Testosterone again in in HFCS receiving animals was noted in 15 days interval hormonal studies and even after 90 days of administration, which were all in significant manners .

\subsection{Uterine Necropsy and Histopathology}


As shown in table 1, the total weight of uterus was significantly increased in HFCS55-Fed group $(1.4115 \pm 0.052$ vs. $1.1975 \pm 0.050, p=0.0182)$ compared to control. The same difference was detected between HFCS fed animals and sucrose fed animals ( $1.4115 \pm 0.052$ vs. $1.2102 \pm 0.047, p=0.0209)$. HFSC intake was accompanied by destructive changes in the uterus of animals that means

squamous metaplasia in uterine tissue of HFCS fed animals was detected (Fig $1 \mathrm{~A}$ ). Endometrial cells with apoptosis in HFCS fed animals (Fig1 B) and endometrial apoptosis with PMN cell infiltration and inflammatory changes in lamina propia in HFCS fed animals were the other detected destructive changes which observed.

\subsection{Ovarian Necropsy and Histopathology}

As shown in table 1, the total weight of ovaries were significantly increased in HFCS55-Fed animals $(0.3528 \pm 0.070$ vs. $0.2993 \pm 0.072, p<0.0001)$ compared to control. The same difference was detected between HFCS fed animals and sucrose fed animals $(0.3528 \pm 0.070$ vs. $0.3025 \pm 0.069, p<0.0001$. HFSC intake was accompanied by destructive changes in the ovaries. The control and Sucrose-Fed groups demonstrated normal basic ovarian structure which usually contains corpus luteum and all developmental stages of follicles but moderate to severe congestion in ovarian tissue of HFSC fed animals were observed (Fig 1B1).

\subsection{Immunohistochemical Expression of Androgen Receptor}

Table 2 compares the expression levels of Androgen Receptor (AR) based on Propotion score (P), intensity score $(I)$ and Allred score $(P+I)$ in Epithelial cells of ovary follicles and Ovarian superficial epithelium.AR was overexpressed in ovaries of HFSC fed animals according to Propotion Score, AR Intensity Score and allred score but similar to control group, the expression pattern of AR remained unchanged in sucrose fed animals.

Fig 1 compares AR expression among study groups. AR expression was mild to negative in epithelial cells of ovary follicles and ovarian superficial epithelium of animals in control and sucrose groups (Fig1A2) but AR expression in epithelial cells of ovary follicles was strong (3+) and moderate (2+) in ovarian superficial epithelium (Fig1B1, B2) and ovarian superficial (Fig 1C epithelium of HFCS fed animals showed similar pattern of AR expression in sucrose fed animals.

\subsection{Uterine Expression of Androgen Receptor (AR)}

Mild Nuclear expression of AR in endometrial epithelium of HFCS fed animals (Fig 2D) and moderate nuclear expression of AR in endometrial epithelium of Sucrose fed animals (Fig 2E) was detected .AR expression in endometrial epithelium of control group was strong (Fig $2 \mathrm{~F}$ ).

\section{Immunohistochemical expression Estrogen Receptor}

Table 2 compares the expression levels of Estrogen Receptor (ER) based on Propotion score (P), intensity score $(\mathrm{I})$ and Allred score $(\mathrm{P}+\mathrm{I})$ in Epithelial cells of ovary follicles and Ovarian superficial epithelium.ER expression pattern was practically similar in ovaries of study groups. 


\subsection{Lipid profile}

As shown in table 3 , all lipid profile factors in HFCS-55 fed rats significantly increased compared to control and Sucrose groups except HDL-Cholesterol. Out of different lipid profile related factors, LDL-Cholesterol and LDL/HDL ratio raised significantly just in HFCS-55 fed animals $(p=0.008)$ not in sucrose group. Other factors changed in the following manner:

- Triglyceride (TG mg/dL): Serum level of TG in HFCS-55 was significantly higher than control $(p<0.0001)$ and Sucrose $(p=0.0034)$.

- Serum level of total Cholesterol raised significantly in both treatment groups compared to control but the difference was higher in HFCS-55 $(p=0.0095)$ than Sucrose $(p=0.045)$.

- Non-HDL Cholesterol also increased significantly in both treatment groups compared to control but the difference was again higher in HFCS-55 $(p=0.0021)$ than Sucrose $(p=0.0062)$.

- Cholesterol/HDL ratio was increased in both groups but the level in HFCS-55 fed animals was significantly higher $(p=0.0165)$.

\subsection{Glycemic factors}

As shown in table 3, out of different glycemic factors, FBS increased in both study groups but the mean (SD) was significantly higher in HFCS-55 compared to control $(125 \pm 17.21918 v s .79 \pm 15.033, p=0.002)$ and the difference with Sucrose was not meaningful $(p=0.6302)$.

\section{Discussion}

Global prevalence of primary ovarian insufficiency (POI) is continuously growing with partially or complete cessation of ovarian function (Golezar S, 2019) but more than one fourth of Iranian women experience early menopause before 45 , especially the non-normal weight ones and this high prevalence should be considered as a critical public health concerns that needs to be addressed by health policy makers (Marzieh Rostami Dovom, 2021). Our recent study on the contribution of dietary factors in ovarian toxicity (Bidgoli SA, 2021) has encouraged us to focus on the role of other routine nutritional parameters in ovarian dysfunction and selected fructose-rich diet for this purpose. To achieve this goal, we tried in this 90 days study to compare the reproductive effects of HFCS-55 enriched normal chow diet with two control groups (normal chow diet and sucrose enriched normal chow diet) through clinical, biochemical , hormonal ,histopathological and immunohistochemucal analysis. In the context of many expectable changes in total body weight, glycemic factors and lipid profile in both fructose and sucrose fed animals (table 2), differential toxic reactions in HFCS-55 fed animals were accompanied by destructive changes in ovaries and uterine according to necrospsy,histopathologica and immunohistochemical changes compared to sucrose fed animals. Highly significant increase in FSH and LH levels, meaningful lower serum testosterone and estradiol levels and extensive AR overexpression in reproductive tissues of HFCS group of animals are thought-provoking signs and signals of fructose induced reproductive toxicity in this model which is discussing below. 
Development of hyper-gonadotropic hypoestrogenism signs and symptoms in women before 40 years of age is referred as premature ovarian failure (POF), or "premature ovarian insufficiency" (POI) (Marzieh Rostami Dovom, 2019). The idiopathic trio of POI could be associated with increased risk of idiopathic infertility, cardiovascular disease (CVD), decreased bone mineral density (BMD), vulvovaginal atrophy, psychological distress, neurological effects and overall reduced quality of life and life expectancy (Tsiligiannis S, 2019), (Rossetti R, 2017). Through animal studies, normally mature Rats with fully developed hypothalamic-pituitary-gonadal (HPG) axis and serum androgen-estrogen levels are susceptible to xenobiotic induced ovarian dysfunction and our findings clearly confirmed this sensitivity to dietary high-fructose intake in female rats. Female rat susceptibility to high-fructose diet was confirmed by higher LH and FSH levels $(p<0.001)$, lower serum testosterone levels $(p=0.0032)$, lower serum estradiol levels $(p<0.001)$, increased total body weight $(p=0.0094)$, higher levels of serum lipids $(p=0.001)$ and increased FBS $(p=0.002)$ compared to control groups. This pattern was partially described elsewhere in male rats with high fructose diet before (Tkachenko OY, 2020). Based on these findings further epidemiological studies seems necessary to find any possible association between high-fructose diet and POI in Iranian /middle east women espceially in overweight cases .

The endometrium is a complex multicellular tissue which is extensively sensitive to the synthesis and release of sex steroids in the ovary (Gibson DA, 2020), a process which was obviously disturbed in our HFCS-55 fed animals. The structural impact of estradiol and testosterone deficiency on endometrial tissue was accompanied by uterine metaplasia, apoptotic changes and initial evidence of inflammation by Neutrophil (PMN) infiltration which plays a central role in inflammation and could be considered as a major cause of tissue damage. These battery of changes are initial evidence for possible later clinical diseases especially infertility, endometriosis (Vercellini P, 2014) and reproductive malignancies (PP., 2018) by summarizing evidence from studies on these issues. Based on these preliminary findings with significant uterus weigh in HFCS-fed animals further epidemiological studies seems necessary to find any possible association between high-fructose diet and endometrial malignancy,infertlity and endometriosis especially in overweight, hyperglycemic or hyperlipidemic women .

The ovary, is one of the main sources of androgen production in women. A detailed evidence of Androgen Receptor overexpression in ovary and endometrial tissues of HFCS-55 fed animals in parallel to testosterone deficient are good evidence which was associated with ovarian congestion in this group of animals but further studies on sex hormone binding globulin (SHBG), free androgen index (FAI)(Santoro N, 2011) in animal and epidemiological studies seems necessary. We predict also overexpression of ER in longer study design according to significant estradiol deficiency in present study and PR downregulation based on overproduction in this study setting.

\section{Conclusion}

Using verified OECD guideline (TG 408) and evaluation of sub chronic oral toxicity of HFCS- 55 commercial samples in original dilution in an ad libitum oral 90 days intake model, suggests the hypothesis that highfructose diet can induce primary ovarian insufficiency, uterine metaplasia and inflammation by 
meaningful hormonal, histopathological and immunohistochemical evidence. We strongly believe that reproducibility of present results should be assessed in similar setting using HFCS- 55 derived food products. Based on recent published literature on toxic effects of high-fructose diet and present study results on differential role of HFSC-55 on female reproductive and hormonal functions, continued use of HFCS-55 in the food industries with existing governmental standards and requirements may need some revisions. Human population studies in exposed populations is also necessary to understand possible associations between growing incidence of $\mathrm{POI}$ and dietary fructose as a very important public women health issue in parallel to more experimental studies to define new necessary policies in the future.

\section{Declarations}

Acknowledgements The authors are thankful from Zar Fructose Co., Ltd., Tehran, Iran for providing our study samples. The authors also acknowledge Dr. Hasti Azar Abad as the veterinary pathologist of the present study for her excellent supports of histopathological studies. We acknowledge cancer Institute of Iran for supporting immunohistochemical analysis .

\section{Author contribution}

Roya Mirzaei performed all animal studies and lab as part of her PhD thesis. She read and approved the manuscript before submission. Sepideh Arbabi Bidgoli is the main supervisor of this study who planned, designed the work, conducted, performed the statistical analysis, and provided the manuscript. Roya Khosrokhavar was the second supervisor of this PhD study who suggested the main topic and contributed in planning and study design execution of HFCS-55. Shahram Shoeibi and Hamidreza Ahmadi Ashtiani were co-advisors of this $\mathrm{PhD}$ program who were contributed to all parts of this study.

Availability of data and materials: All data and materials are available upon journal request.

Declarations Ethical approval: This study was approved by the ethics committee of Islamic Azad University, Tehran Medical Sciences (IAUTMU) under the number of IR. IAU. TMU REC.1399.216.

Consent to participate: Not applicable.

Consent for publication: The authors ensure that this Journal and the Publisher have the Author's permission to publish the relevant Contribution.

Competing interests: The authors declare no competing interests.

Funding Resource: Not applicable.

\section{References}

\section{Akarca-Dizakar Sö Erdoğan D, Peker T, Coşkun Akçay N, Türkoğlu I, Eşmekaya MA, Ömeroğlu S.} Effects of co-administered melatonin, fructose and bisphenol A (BPA) on rat epididymis and sperm characteristics [Journal] // Biotech Histochem.. - 2020. - 1 : Vol. 95. - pp. 18-26. 
2. Bhat SF Pinney SE, Kennedy KM, McCourt CR, Mundy MA, Surette MG, Sloboda DM, Simmons RA. Exposure to high fructose corn syrup during adolescence in the mouse alters hepatic metabolism and the microbiome in a sex-specific manner [Journal] // J Physiol. . - 2021. - 5 : Vol. 599. - pp. 1487-1511..

3. Bidgoli SA Ahmadi R, Zavarhei MD Role of hormonal and environmental factors on early incidence of breast cancer in Iran [Journal] // Sci Total Environ. - 2010. - 19 : Vol. 408. - pp. 4056-61.

4. Bidgoli SA Arabshahi P, Ramezan Y. Ovarian toxicity of plant-derived edible oils: a 28 days hormonal and histopathological study in Wistar rat [Journal] // Environ Sci Pollut Res Int. - Sep 8 , 2021.

5. Bidgoli SA Karimi M, Asami Z, Baher H, Djamali Zavarhei M. Association between testicular Aryl hydrocarbon Receptor levels and idiopathic male infertility: a case-control study in Iran [Journal] // Sci Total Environ. . - 2011. - 18 : Vol. 409. - pp. 3267-73..

6. Chenxia Dai Tingting Miao, Jinping Hai, Yunyi Xiao, Ying Li, Junren Zhao, Hulin Qiu, Bo Xu A Novel Glucose Isomerase from Caldicellulosiruptor bescii with Great Potentials in the Production of HighFructose Corn Syrup [Journal] // Biomed Res Int. . - 2020. - 1871934. : Vol. 2020.

7. Collison KS Saleh SM, Bakheet RH, Al-Rabiah RK, Inglis AL, Makhoul NJ, Maqbool ZM, Zaidi MZ, AlJohi MA, Al-Mohanna FA. Diabetes of the liver: the link between nonalcoholic fatty liver disease and HFCS-55 [Journal] // Obesity (Silver Spring). . - 2009 . - 11 : Vol. 17. - pp. 2003-13. .

8. de Melo GB Soares JF, Costa TCL, Benevides ROA, Vale CC, Paes AMA, Gaspar RS. Early Exposure to High-Sucrose Diet Leads to Deteriorated Ovarian Health [Journal] // Front Endocrinol (Lausanne). 2021. - Vol. 12. - p. 656831. .

9. DeChristopher LR Auerbach BJ, Tucker KL. High fructose corn syrup, excess-free-fructose, and risk of coronary heart disease among African Americans- the Jackson Heart Study [Journal] // BMC Nutr. . 2020. - 1 : Vol. 6. - p. 70.

10. Gibson DA Simitsidellis I, Collins F, Saunders PTK. Androgens, oestrogens and endometrium: a fine balance between perfection and pathology [Journal] // J Endocrinol. . - 2020. - 3 : Vol. 246. - pp. R75R93. .

11. Golezar S Ramezani Tehrani F, Khazaei S, Ebadi A, Keshavarz Z. The global prevalence of primary ovarian insufficiency and early menopause: a meta-analysis [Journal] // Climacteric. . - 2019. - 4 : Vol. 22. - pp. 403-411. .

12. Goncalves MD Lu C, Tutnauer J, Hartman TE, Hwang SK, Murphy CJ, Pauli C, Morris R, Taylor S, Bosch K, Yang S, Wang Y, Van Riper J, Lekaye HC, Roper J, Kim Y, Chen Q, Gross SS, Rhee KY, Cantley LC, Yun J. High-fructose corn syrup enhances intestinal tumor growth in mice. [Journal] // Science. - 2019. 6433 : Vol. 363. - pp. 1345-1349..

13. Ishikawa H Hashimoto S, Ohashi K. Maternal fructose intake disturbs ovarian estradiol synthesis in rats [Journal] // Life Sci. . - 2018. - 202. - pp. 117-123..

14. M. Rodgers B. Heineman, J. Dushay Increased fructose consumption has sex-specific effects on fibroblast growth factor 21 levels in humans [Journal] // Obes Sci Pract. . - 2019. - 5 : Vol. 5. - pp. 503510. . 
15. Marzieh Rostami Dovom Mahsa Noroozzadeh, Nariman Mosaffa, Azita Zadeh-Vakili, Abbas Piryaei, Fahimeh Ramezani Tehrani Induced premature ovarian insufficiency by using $D$ galactose and its effects on reproductive profiles in small laboratory animals: a systematic review [Journal] // J Ovarian Res.. - 2019. - Vol. 12. - p. 96.

16. Marzieh Rostami Dovom Razieh Bidhendi-Yarandi, Kazem Mohammad, Maryam Farahmand, Fereidoun Azizi, Fahimeh Ramezani Tehrani Prevalence of premature ovarian insufficiency and its determinants in Iranian populations: Tehran lipid and glucose study [Journal] // BMC Womens Health. . - 2021. - Vol. 21. - p. 79.

17. Michael I. Goran Ashley A. Martin, Tanya L. Alderete, Hideji Fujiwara, David A. Fields Fructose in Breast Milk Is Positively Associated with Infant Body Composition at 6 Months of Age [Journal] // Nutrients.. 2017. - 2 : Vol. 9. - p. 146.

18. Paige K. Berger David A. Fields, Ellen W. Demerath, Hideji Fujiwara, Michael I. Goran High-Fructose Corn-Syrup-Sweetened Beverage Intake Increases 5-Hour Breast Milk Fructose Concentrations in Lactating Women [Journal] // Nutrients. - 2018. - 6 : Vol. 10. - p. 669.

19. PP. Ip Benign endometrial proliferations mimicking malignancies: a review of problematic entities in small biopsy specimens [Journal] // Virchows Arch.. - 2018. - 6 : Vol. 472. - pp. 907-917..

20. Rizk MG Thackray VG. Intersection of Polycystic Ovary Syndrome and the Gut Microbiome [Journal] // J Endocr Soc. . - 2020. - 2 : Vol. 5. - p. bvaa177.

21. Rossetti R Ferrari I, Bonomi M, Persani L. Genetics of primary ovarian insufficiency [Journal] // Clin Genet. . - 2017. - 2 : Vol. 91. - pp. 183-198. .

22. Sadowska J Rygielska M. The effect of high fructose corn syrup on the plasma insulin and leptin concentration, body weight gain and fat accumulation in rat [Journal] // Adv Clin Exp Med. . - 2019 . - 7 : Vol. 28. - pp. 879-884..

23. Santoro N Randolph Jr JF Reproductive Hormones and the Menopause Transition [Journal] // Obstet Gynecol Clin North Am. . - 2011. - 3 : Vol. 38. - pp. 455-466..

24. Semnani-Azad Z Khan TA, Blanco Mejia S, de Souza RJ, Leiter LA, Kendall CWC, Hanley AJ, Sievenpiper JL Association of Major Food Sources of Fructose-Containing Sugars With Incident Metabolic Syndrome: A Systematic Review and Meta-analysis [Journal] // JAMA Netw Open. . - 2020. 7 : Vol. 3. - p. e209993..

25. Tkachenko OY Shayakhmetova GM, Matvienko AV, Kovalenko VM. Reproductive disorders in male rats induced by high-fructose consumption from juvenile age to puberty [Journal] // Arh Hig Rada Toksikol. - 2020. - 1 : Vol. 71. - pp. 78-86. .

26. Tsiligiannis S Panay N, Stevenson JC. Premature Ovarian Insufficiency and Long-Term Health Consequences [Journal] // Curr Vasc Pharmacol.. - 2019. - 6 : Vol. 19. - pp. 604-609. .

27. Vercellini P Viganò P, Somigliana E, Fedele L. Endometriosis: pathogenesis and treatment. [Journal] // Nat Rev Endocrinol.. - 2014. - 5 : Vol. 10. - pp. 261-75..

28. Zargaraan A Kamaliroosta L, Seyed Yagoubi A, Seyed Yagoubi L, Mirmoghtadaie L, Effect of Substitution of Sugar by High Fructose Corn Syrup on the Physicochemical Properties of Bakery and 
Dairy Products: A Review [Journal] // Nutrition and Food Sciences Research . - 2016. - 4 : Vol. 3. - pp. 311.

29. Zhou Y Chi J, Lv W, Wang Y. Obesity and diabetes as high-risk factors for severe coronavirus disease 2019 (Covid-19) [Journal] // Diabetes Metab Res Rev. - 2021 . - 2 : Vol. 37. - p. e3377.

\section{Tables}

Table 1. Comparison of total body weight, organ weights and serum sex hormones between HFCS- 55 and controls at day 90 (mean \pm SD)

\begin{tabular}{|c|c|c|c|c|c|}
\hline \multirow[t]{2}{*}{ Parameters } & \multicolumn{3}{|l|}{ Groups } & \multirow[t]{2}{*}{$P$ value $\mathrm{A}^{1}$} & \multirow{2}{*}{$\begin{array}{l}P \text { value } \\
\mathrm{B}^{2}\end{array}$} \\
\hline & Control & Sucrose & HFCS-55 & & \\
\hline $\begin{array}{l}\text { Total Body Weight } \\
\text { (g) }\end{array}$ & $230.52 \pm 0.84$ & $\begin{array}{l}275.82 \pm \\
6.6237\end{array}$ & $267.62 \pm 4.61$ & $0.0094 * \star$ & NS \\
\hline Uterus weight (g) & $1.1975 \pm 0.050$ & $1.2102 \pm 0.047$ & $1.4115 \pm 0.052$ & $0.0182^{*}$ & $0.0209 *$ \\
\hline Ovarian weight (g) & $0.2993 \pm 0.072$ & $0.3025 \pm 0.069$ & $0.3528 \pm 0.070$ & $<0.0001 * \star \star$ & $<0.001 * \star \star$ \\
\hline $\mathrm{LH}(\mathrm{IU} / \mathrm{mL})$ & $0.1(0.001)$ & $0.11(0.02)$ & $0.14(0.08)$ & $0.031^{\star}$ & $0.042^{*}$ \\
\hline $\mathrm{FSH}(\mathrm{IU} / \mathrm{mL})$ & $0.11(0.01)$ & $0.112(0.02)$ & $0.129(0.01)$ & $0.0133^{*}$ & $0.036^{*}$ \\
\hline Testosterone(ng/ml) & $0.222(0.103)$ & $\begin{array}{l}0.1156 \\
(0.102)\end{array}$ & $\begin{array}{l}0.0294 \\
(0.002)\end{array}$ & $0.0032 * *$ & $0.027 *$ \\
\hline Progesterone $(\mathrm{ng} / \mathrm{ml})$ & $17.046 \quad(6.56)$ & $\begin{array}{l}28.79 \\
(20.00)\end{array}$ & $42.04(16.74)$ & $0.006 *$ & 0.515 \\
\hline Estradiol(pg/ml) & $\begin{array}{l}25.12 \\
(14.50)\end{array}$ & $\begin{array}{c}14.66 \\
(5.70)\end{array}$ & $\begin{array}{l}7.28 \\
(4.55)\end{array}$ & $<0.0001 * \star \star$ & $0.005^{\star \star}$ \\
\hline
\end{tabular}

${ }^{1} \mathrm{~A}$ means statistical difference between HFCS-55-fed group and control

${ }^{2} \mathrm{~B}$ means statistical difference between Sucrose fed group and HFCS-55-fed group

$(\star \star \star \star ~ p<0.0001, * \star \star ~ p<0.001 . * \star p<0.01, * p<0.05)$.

Table 2: Total immunohistochemical scores of Androgen Receptor (AR) and Estrogen Receptor between in reproductive organs of female rats (Uterine and ovaries) in Uterine and Ovaries and Comparison of the expression patterns between HFCS- 55 fed animals controls at day 90 (mean \pm SD) 


\begin{tabular}{|c|c|c|c|c|c|}
\hline \multirow[t]{2}{*}{ Parameters } & \multicolumn{3}{|c|}{ Groups (each 5 slides) } & \multirow[t]{2}{*}{$P$ value $A^{1}$} & \multirow[t]{2}{*}{$P$ value $\mathrm{B}^{2}$} \\
\hline & Control & Sucrose & HFCS-55 & & \\
\hline \multicolumn{6}{|l|}{ Androgen Receptor(AR) } \\
\hline AR Propotion Score $(\mathrm{P})$ & $2.2(0.447)$ & $1.2(0.447)$ & $3.2(0.447)$ & $0.008^{\star \star}$ & $0.001 * \star \star$ \\
\hline AR Intensity score(I) & $1.4(0.547)$ & 1.0 & $2.4(0.547)$ & $0.02 *$ & $<0.001^{\star \star *}$ \\
\hline AR Allred score $(P+I)$ & $3.6(0.547)$ & $2.2(0.447)$ & $5.6(0.894)$ & $0.003^{\star \star}$ & $<0.001^{\star \star *}$ \\
\hline \multicolumn{6}{|l|}{ Estrogen Receptor(ER) } \\
\hline ER Proportion Score(P) & $2.6(0.547)$ & $3.8(0.447)$ & $3.0(0.707)$ & 0.347 & 0.065 \\
\hline ER Intensity score(I) & 2.0 & $2.2(0.447)$ & 2.0 & $N D^{3}$ & 0.347 \\
\hline ER Allred score $(\mathrm{P}+\mathrm{I})$ & $4.6(0.54)$ & 6.0 & $5.0(0.707)$ & 0.347 & 0.113 \\
\hline
\end{tabular}

${ }^{1}$ A means statistical difference between HFCS-55-fed group and control

${ }^{2} \mathrm{~B}$ means statistical difference between Sucrose fed group and HFCS-55-fed group

$(\star \star \star \star p<0.0001, * \star \star p<0.001 . * \star p<0.01, * p<0.05)$.

${ }^{3}$ Not Determined

Table3: Comparison of Lipid profile and Glycemic factors between HFCS-55 and controls at day 90 (mean \pm SD) 


\begin{tabular}{|c|c|c|c|c|c|}
\hline \multirow[t]{2}{*}{ Parameters } & \multicolumn{3}{|l|}{ Groups } & \multirow[t]{2}{*}{$P$ value $\mathrm{A}^{1}$} & \multirow{2}{*}{$\begin{array}{l}P \text { value } \\
\mathrm{B}^{2}\end{array}$} \\
\hline & Control & Sucrose & HFCS-55 & & \\
\hline \multirow[t]{2}{*}{ Triglyceride(mg/dL) } & $34.2 \pm 4.08656$ & $49 \pm 8.544$ & $74.6 \pm 11.01363$ & & \\
\hline & & & & $<0.0001^{\star \star \star \star}$ & $\underset{* \star}{0.0034}$ \\
\hline $\begin{array}{l}\text { Total } \\
\text { Cholesterol(mg/dL) }\end{array}$ & $57.6 \pm 11.39298$ & $75.6 \pm 12.89574$ & $83 \pm 12.26784$ & 0.0095 ** & 0.3797 \\
\hline $\begin{array}{l}\text { HDL- } \\
\text { Cholesterol(mg/dL) }\end{array}$ & $39 \pm 6.81909$ & $44.2 \pm 9.23038$ & $41.4 \pm 4.72229$ & $N S^{3}$ & NS \\
\hline $\begin{array}{l}\text { Non-HDL } \\
\text { Cholesterol(mg/dL) }\end{array}$ & $18.6 \pm 6.80441$ & $31.4 \pm 3.78153$ & $41.6 \pm 9.26283$ & 0.0021 ** & NS \\
\hline $\begin{array}{l}\text { Cholesterol/HDL } \\
\text { ratio }\end{array}$ & $1.478 \pm 0.15189$ & $1.72 \pm 0.07583$ & $2.004 \pm 0.19591$ & 0.0015 ** & $\begin{array}{l}0.0165 \\
*\end{array}$ \\
\hline $\begin{array}{l}\text { LDL- } \\
\text { Cholesterol(mg/dL) }\end{array}$ & $19.4 \pm 4.97996$ & $26 \pm 5.47723$ & $29.8 \pm 4.38178$ & 0.0080 ** & NS \\
\hline LDL/HDL ratio & $0.496 \pm 0.09915$ & $0.594 \pm 0.08989$ & $0.726 \pm 0.10807$ & 0.0080 ** & NS \\
\hline $\mathrm{FBS}(\mathrm{mg} / \mathrm{dL})$ & $79 \pm 15.033$ & $138.8 \pm 59.20895$ & $125 \pm 17.21918$ & 0.0020 ** & NS \\
\hline HbA1c (\%) & $3.756 \pm 0.14381$ & $3.78 \pm 0.14832$ & $3.738 \pm 0.4077$ & NS & NS \\
\hline $\begin{array}{l}\text { HbA1c (IFCC) } \\
(\mathrm{mM} / \mathrm{M})\end{array}$ & $17.6 \pm 1.51658$ & $17.8 \pm 1.48324$ & $19 \pm 1.87073$ & NS & NS \\
\hline $\begin{array}{l}\text { Estimated Average } \\
\text { Glucose (eAG) } \\
(\mathrm{mg} / \mathrm{dL})\end{array}$ & $61 \pm 4.30116$ & $61.6 \pm 4.15933$ & $65 \pm 5.6249$ & NS & NS \\
\hline
\end{tabular}

${ }^{1} \mathrm{~A}$ means statistical difference between HFCS-55-fed group and control

${ }^{2} B$ means statistical difference between Sucrose fed group and HFCS-55-fed group

$\left({ }^{\star \star \star *} p<0.0001,{ }^{* \star \star} p<0.001 .{ }^{* \star} p<0.01, * p<0.05\right)$.

${ }^{3}$ Not Significant

\section{Figures}

Figure 1 
Histopathological effects of HFCS-55 in uterine and ovaries tissues in compared to control and sucrose fed animals. Photomicrographs stained with hematoxylin and eosin and showed in two magnifications. A: Control and sucrose fed animals show normal uterus with endometrial glands in proliferative phase. B1: Squamous metaplasia in uterine tissue of HFCS fed animals. B2: Endometrial apoptosis with PMN cell infiltration in lamina propia in HFCS fed animals .B3: B2Endometrial cells with apoptosis in HFCS fed animals.C: Normal ovarian tissue with prominent corpus luteum in control group. D: normal ovarian tissue with prominent corpus luteum in sucrose fed animals

\section{Figure 2}

Immunohistochemical expression of Androgen Receptor in ovarian tissues of Wistar rats.

Photomicrographs of sections $A$ and $B$ show negative/mild expression of AR in epithelial cells of ovary follicles and ovarian superficial epithelium in control sucrose groups $(x 100) \cdot C 1(x 100), C 2-4(x 400)$ show strong (3+) expression of AR in epithelial cells of ovary follicles and ovarian superficial epithelium in HFCS55 fed animals

\section{Figure 3}

Immunohistochemical expression of Androgen Receptor in the uterine of Wistar rats. Photomicrographs of sections $A$ and $B$ show negative/mild expression of $A R$ in endometrial epithelium of animals in control and sucrose group .Fig C1-4 shows moderate to strong nuclear expression of AR in in endometrial epithelium of HFCS fed animals. 